\title{
Insulin Sensitizing and Insulinotropic Action of Berberine from Cortidis Rhizoma
}

\author{
Byoung-Seob Ko, ${ }^{a}$ Soo Bong ChOI, ${ }^{b}$ Seong Kyu PARK, ${ }^{c}$ Jin Sun JANG, ${ }^{d}$ Yeong Eun KIM, ${ }^{a}$ and \\ Sunmin PARK ${ }^{*, d}$ \\ ${ }^{a}$ Department of Quality Inspection and Examination, Korea Institute of Oriental Medicine; Daejun, 305-390 Korea: \\ ${ }^{b}$ Department of Internal Medicine, Konkuk University; Chungjoo, Chungbuk, 380-701 Korea: ${ }^{c}$ Department of Oriental \\ Medicine, Kyunghee University; Seoul, 130-701 Korea: ${ }^{d}$ Department of Food and Nutrition, Hoseo University; Asan, \\ Chungnam-do, 336-795 Korea. Received February 25, 2005; accepted May 24, 2005
}

Our preliminary study demonstrated that $70 \%$ ethanol Cortidis Rhizoma extracts (CR) had a hypoglycemic action in diabetic animal models. We determined whether $C R$ fractions acted as anti-diabetic agent, and a subsequent investigation of the action mechanism of the major compound, berberine $\left(\left[\mathrm{C}_{20} \mathrm{H}_{18} \mathrm{NO}_{4}\right]^{+}\right)$, was carried out in vitro. The 20, 40 and $60 \%$ methanol fractions from the XAD-4 column contained the most insulin sensitizing activities in 3T3-L1 adipocytes. The common major peak in these fractions was berberine. Treatment with $50 \mu \mathrm{M}$ berberine plus differentiation inducers significantly reduced triglyceride accumulation by decreased differentiation of 3T3-L1 fibroblasts to adipocytes and triglyceride synthesis. Significant insulin sensitizing activity was observed in 3T3-L1 adipocytes which were given $50 \mu_{\mathrm{M}}$ berberine plus $0.2 \mathrm{~nm}$ insulin to reach a glucose uptake level increased by $10 \mathrm{~nm}$ of insulin alone. This was associated with increased glucose transporter-4 translocation into the plasma membrane via enhancing insulin signaling pathways and the insulin receptor substrate-1-phosphoinositide 3 Kinase-Akt. Berberine also increased glucose-stimulated insulin secretion and proliferation in Min6 cells via an enhanced insulin/insulin-like growth factor-1 signaling cascade. Data suggested that berberine can act as an effective insulin sensitizing and insulinotropic agent. Therefore, berberine can be used as anti-diabetic agent for obese diabetic patients.

Key words 3T3-L1 adipocytes; Min6 cell; insulin secretion; IRS1; Akt; GLUT4

Type 2 diabetes is a heterogeneous metabolic disorder characterized by the impairment of insulin secretion from pancreatic $\beta$-cells and insulin resistance in peripheral tissues such as the liver, skeletal muscle and adipose tissue. ${ }^{1)}$ In most cases, insulin resistance mostly precedes the impairment of insulin secretion in humans. For example, obesity induces hepatic, skeletal muscle and adipocyte insulin resistance, and hypersecretion of insulin maintains normoglycemia by compensating for insulin resistance. As long as insulin secretion compensates for peripheral insulin resistance, diabetes is not developed and exacerbated. Thus, herbs or drugs for type 2 diabetes mellitus should have an insulin sensitizing action to relieve insulin resistance and an insulinotropic action to improve glucose-stimulated insulin secretion and pancreatic $\beta$-cell survival.

Extracts from Coptidis Rhizoma (CR) and Cortex Phellodendri, a Southeast Asian herb, have been used to treat diabetes mellitus for more than one thousand years in the history of Chinese medicinal remedies. ${ }^{2,3)}$ Berberine $\left(\left[\mathrm{C}_{20} \mathrm{H}_{18} \mathrm{NO}_{4}\right]^{+}\right)$, one of the main constituents of $\mathrm{CR}$ and Cortex Phellodendri, is a type of isoquinoline alkaloid, suggesting that it is a candidate of the principal anti-diabetic constituents of CR. According to reports, ${ }^{2-4)}$ berberine acts as an $\alpha$-adrenoceptor antagonist. In addition, some $\alpha$ adrenoceptor antagonists, such as phentolamine, stimulate insulin release by inhibiting pancreatic $\beta$-cell ATP-sensitive potassium channels. ${ }^{5,6)}$

Berberine is a candidate for insulin secretagogues, but it's effect was not sufficient to recommend CR or berberine to treat type 2 diabetes. Post-prandial hyperglycemia is a prominent early defect in type 2 diabetes, predominantly due to loss of acute phase insulin secretion after eating. ${ }^{7,8)}$ Thus, insulin secretagogues have long been used as a diabetic drug to reduce post-prandial hyperglycemia to normal levels. Insulin secretagogues such as sulfonylurea make normoglycemia in the early stage of diabetes. However, most of them stimulate insulin secretion with and without glucose challenge by closing ATP-sensitive potassium channels in $\beta$-cells. ${ }^{7,8}$ As a result, they increase insulin secretion without glucose loading, resulting in exhausting and damaging $\beta$-cells and frequent hypoglycemia. Eventually, they exacerbate the symptoms of diabetes. The ideal agent to treat post-prandial hyperglycemia should restore the acute-phase insulin secretion without hypoglycemia and enhance pancreatic $\beta$-cell survival. Thus, an insulinotropic agent is a better anti-diabetic agent than a simple insulin secretagogue. Insulinotropic agents, such as glucagon like peptide-1 receptor agonist (exendin-4), improve glucose-stimulated acute insulin secretion with the expansion of $\beta$-cell mass through improving insulin like growth factors (IGF)-1 and/or insulin. ${ }^{9-11)}$

In the present study, the fractions of CR were investigated for their effects as an insulin sensitizer through insulin-mediated glucose uptake in 3T3-L1 adipocytes and as an insulinotropic agent in Min6 cells. Subsequently, the mechanism of insulin sensitizing and insulinotropic action of berberine, the major compound of CR in effective fractions, was determined in a cell-based system.

\section{MATERIALS AND METHODS}

Fractionation of CR Extract CR fractions were prepared by the method described previously ${ }^{12)}$ with modifications. Briefly, CR was extracted with $70 \%$ ethanol $(\mathrm{EtOH})$ at $50{ }^{\circ} \mathrm{C}$ for $12 \mathrm{~h}$. The concentrated extracts were divided into 5 fractions by column chromatography on Amberlite XAD-4 polymeric resin (Sigma, St. Louis, MO, U.S.A.) eluting with 
a stepwise gradient of $\mathrm{MeOH}$-water $(0,20,40,60,80$, $100 \%$ ) (Fig. 1). Each fraction was filtered with a $0.4-\mu \mathrm{m}$ filter and concentrated by heat evaporation and lysophilization. The powder was dissolved in sterile dimethyl sulfoxide (DMSO, Sigma) to $1 \mathrm{mg} / \mathrm{ml}$, and then further diluted with a sterile phosphate buffered saline (PBS) or media to the appropriate concentrations $(0.5$ and $5 \mu \mathrm{g} / \mathrm{ml})$.

The components of the fraction were identified with a high performance liquid chromatography analysis (HPLC; Waters Co., Milford, MA, U.S.A.). Each fraction was spotted in a silica gel TLC plate (chloroform/methanol/water $=4 / 1 / 0.1$ and 7/4/1) and the number of components were identified. Fractions were injected in an octadecylsilane column, 4.6X $250 \mathrm{~mm}$ (Alltech Associates, Deerfield, IL) at $40^{\circ} \mathrm{C}$ in HPLC analysis. The mobile phase was a gradient of $10 \mathrm{mmol} / 1$ phosphoric acid (solvent A) and acetonitrile (solvent B) at a flow rate of $1 \mathrm{ml} / \mathrm{min}$ with $35 \%$ solvent $B$ for $15 \mathrm{~min}$ and linear increase from $35 \%-90 \%$ of solvent B. Peaks were detected at a wavelength of $254 \mathrm{~nm}$. The contents were confirmed by an external standards, alkaloids and isoflavonoids (Sigma, St. Louis, MO, U.S.A.).

3T3-L1 Fibroblast Differentiation into Adipocytes 3T3-L1 fibroblasts were grown, maintained and differentiated into adipocytes in high glucose Dulbecco's Modified Eagle's Medium (DMEM; Invitrogen, Carlsbad, CA, U.S.A.) as previously described. ${ }^{12,13)}$ To determine berberine effects on 3T3-L1 fibroblast differentiation into adipocytes as triglyceride accumulation, a vehicle (DMSO) or 5 or $50 \mu \mathrm{M}$ berberine (Sigma) was added into the media with differentiation inducers, $1 \mathrm{mg} / \mathrm{ml}$ insulin (Sigma), $50 \mu \mathrm{M}$ dexamethasone (Sigma), and $0.8 \mathrm{~mm}$ isobutylmethyl xanthine (Sigma), for $4 \mathrm{~d}$. From day 5 , the vehicle or berberine was freshly added without the inducers whenever the media was replaced. At day 10 from the initiation of differentiation, the cells were harvested with lysis buffer without glycerol, and the cellular triglyceride contents were measured by Trinder kit. (Young Dong Pharmaceutical Co., Seoul).

Insulin-Stimulated Glucose Uptake Assay in 3T3-L1 Adipocytes Between 9 and 12 d after 3T3-L1 fibroblasts was initiated to differentiate with the differentiation inducers in high glucose DMEM, 3T3-L1 adipocytes were used for determining berberine effect on insulin-stimulated glucose uptake. The glucose uptake activity was analyzed by measuring the uptake of 2-deoxy-D- $\left[{ }^{3} \mathrm{H}\right]$ glucose. ${ }^{12,13)}$ Briefly, 3T3L1 adipocytes in 12-well plates were washed twice with low glucose DMEM and incubated with $1 \mathrm{ml}$ of the same media at $37^{\circ} \mathrm{C}$ for $12 \mathrm{~h}$ with the following drugs; DMSO, 5 or $50 \mu \mathrm{M}$ berberine, 0.5 or $2.5 \mathrm{nM}$ exendin- 4 (Sigma) or 2 or $20 \mu \mathrm{M}$ pioglitazone (Takeda Pharmaceuticals Inc., Lincolnshire, IL, U.S.A.). After washing the cells with a KrebsRinger-Hepes (KRP) buffer, the cells were incubated with the KRP buffer with the addition of respective drugs plus $0.2 \mathrm{~nm}$ insulin or with $10 \mathrm{~nm}$ insulin at $37^{\circ} \mathrm{C}$ for $30 \mathrm{~min}$. At the end of incubation $0.1 \mu \mathrm{Ci}$ 2-deoxy-D- $\left[{ }^{3} \mathrm{H}\right]$ glucose (PerkinElmer Life, Boston, MA, U.S.A.) and $1 \mathrm{~mm}$ glucose as final concentrations was added for $10 \mathrm{~min}$. After terminating the assay with cold PBS, the radioactivity retained by the cell lysates was determined by a scintillation counter. Nonspecific glucose uptake was measured at a glucose concentration of 5.5 mM without insulin.

Min6 Cells Culture Min6 cells were grown in high glu- cose DMEM containing $15 \%(\mathrm{v} / \mathrm{v})$ heat-inactivated fetal bovine serum (Invitrogen), $50 \mu \mathrm{M} \quad \beta$-mercaptoethanol (Sigma), penicillin and streptomycin (Sigma). The cells were maintained at $37^{\circ} \mathrm{C}$ in a humidified atmosphere with $5 \%$ $\mathrm{CO}_{2}$ and used between passages 19 and 30. Min6 cells at $70-80 \%$ confluence were used for glucose-stimulated insulin secretion, $\beta$-cell proliferation and insulin/IGF-1 signaling cascade.

Glucose-Stimulated Insulin Secretion and $\boldsymbol{\beta}$-cell Proliferation Assay Min6 cells in a 24 well plate were washed and incubated with KRP buffer containing $5 \mathrm{mg} / \mathrm{ml}$ bovine serum albumin and $2 \mathrm{~mm}$ glucose (low glucose KRP buffer) for $16 \mathrm{~h}$. The Min6 cells were applied with a vehicle (DMSO), 5 or $50 \mu \mathrm{m}$ berberine in a low or high glucose (20 mM) KRP buffers for $30 \mathrm{~min}$. Insulin concentrations in low and high glucose KRP buffer were measured by radioimmunoassay kit (Linco Research, St. Charles, MO, U.S.A.).

Cell proliferation was measured in Min6 cells treated with 5 and $50 \mu \mathrm{M}$ of berberine and $2.5 \mathrm{~nm}$ of exendin- 4 with a Cell Proliferation WST-1 reagent assay kit from Roche Diagnostic Co (Indianapolis, IN, U.S.A.). The kit is a modified tetrazolium salt that can be cleaved by metabolically active cells to a water soluble formazan, which was quantitated at $450 \mathrm{~nm}$ with an ELISA plate reader.

Immunoprecipitation and Immunoblotting Analyses One day after reseeding into a $5 \mathrm{~cm}^{2}$ dish, 3T3-L1 adipocytes or Min6 cells were incubated with serum free high glucose DMEM with 3\% bovine serum albumin for $12 \mathrm{~h}$. A vehicle (DMSO) or designated concentrations of berberine were added into the plate for $8 \mathrm{~h}$ in both cells. At the end of the treatment, $0,0.2$ or $10 \mathrm{~nm}$ insulin for 3T3-L1 adipocytes and $10 \mathrm{~nm}$ IGF-1 for Min6 cells were treated for $10 \mathrm{~min}$. The cells were lysed in $20 \mathrm{~mm}$ Tris ( $\mathrm{pH} 7.4$ ) containing $2 \mathrm{~mm}$ ethylenediaminetetraacetic acid, $137 \mathrm{~mm} \mathrm{NaCl}, 1 \% \mathrm{NP} 40,10 \%$ glycerol and $12 \mathrm{~mm} \alpha$-glycerol phosphate and protease inhibitors (Sigma) and cell debris was removed by centrifugation. After determining protein content, lysates with equivalent amounts of protein were immunoprecipitated with anti-insulin receptor substrate (IRS)-1 and IRS2 (Upstate Biotechnology Inc, Lake Placid, NY, U.S.A.) antibodies, followed by resolving with SDS-PAGE and immunoblotted with anti-phosphotyrosine protein (py20). IRS1, IRS2 and P85 (Upstate Biotechnology Inc.) were detected after stripping the py20 antibody (Upstate Biotechnology Inc.). Phospho-Akt ${ }^{\mathrm{ser} 478}$, Akt (Cell Signaling Technology, Beverly, MA, U.S.A.), phosphorylated cAMP response element binding protein $(\mathrm{CREB})^{\mathrm{ser} 133}$ and CREB (Upstate Biotechnology Inc.) were measured by immunoblotting with respective antibodies. ${ }^{13,14)}$ Plasma membrane was prepared from the cell lysates, ${ }^{15)}$ and glucose transporter 4 (GLUT4, Chemicon, Temecula, CA, U.S.A.) contents were determined by immunoblotting with antiGLUT4 protein. The intensity of protein expression was determined using Imagequant TL (Amersham Biosciences, Piscataway, NJ). All experiments in this study were repeated at least three times.

Statistical Analysis All results are expressed as a mean \pm standard deviation (S.D.). Statistical analysis was performed using the SAS statistical analysis program. ${ }^{16)}$ Oneway analyses of variance (ANOVA) were carried out in fractionated fractions and berberine. Multiple comparisons of groups treated with different dosages were undertaken by 
Table 1. Insulin-Stimulated Glucose Uptake with Fractionated Extracts from 70\% EtOH Extract of Cortidis Rhizoma in 3T3-L1 Adipocytes and Their Berberine Contents.

\begin{tabular}{|c|c|c|c|c|}
\hline & Vehicle treatment ${ }^{1}(\%)$ & $0.5 \mu \mathrm{g} / \mathrm{ml}$ treatment $(\%)$ & $5 \mu \mathrm{g} / \mathrm{ml}$ treatment $(\%)$ & Berberine content $t^{5}(\%)$ \\
\hline $0 \% \mathrm{MeOH}$ fraction $^{2}$ & $130 \pm 95^{4}$ & $203 \pm 111$ & $256 \pm 105$ & 15.3 \\
\hline $20 \% \mathrm{MeOH}$ fraction & $139 \pm 83^{b}$ & $223 \pm 138^{b}$ & $415 \pm 139^{\mathrm{a} * *}$ & 64.0 \\
\hline $40 \% \mathrm{MeOH}$ fraction & $129 \pm 99^{c}$ & $323 \pm 129^{b}$ & $535 \pm 117^{a * * *}$ & 96.6 \\
\hline $60 \% \mathrm{MeOH}$ fraction & $131 \pm 93^{c}$ & $399 \pm 164^{b}$ & $525 \pm 193^{a * * *}$ & 67.2 \\
\hline $80 \% \mathrm{MeOH}$ fraction & $134 \pm 86^{\mathrm{b}}$ & $253 \pm 151^{\mathrm{ab}}$ & $374 \pm 167^{a *}$ & 38.2 \\
\hline $100 \% \mathrm{MeOH}$ fraction & $127 \pm 99$ & $189 \pm 109$ & $228 \pm 133$ & 10.7 \\
\hline $10 \mathrm{~nm}$ Insulin $^{3}$ & - & $543 \pm 132$ & $538 \pm 153$ & \\
\hline
\end{tabular}

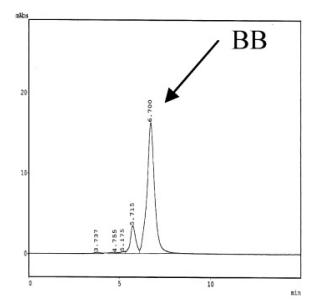

$40 \% \mathrm{MeOH}$ fraction

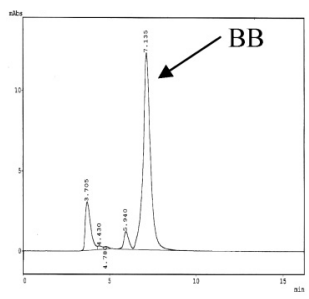

$60 \% \mathrm{MeOH}$ fraction

${ }^{1}$ Vehicle (DMSO) plus $0.2 \mathrm{~nm}$ insulin were treated without any fractions. ${ }^{2}$ The fractions eluted from XAD-4 column with MeOH from Cortidis Rhizoma (CR) extracts were treated for $8 \mathrm{~h}$ in 3T3-L1 adipocytes. At the end of incubation, $0.2 \mathrm{~nm}$ insulin were added into the cells for 30 min to determine which fractions increased insulin-stimulated glucose uptake with low dosage insulin $(0.2 \mathrm{~nm})$. The results were represented as the percent increase of insulin-stimulated glucose uptake from the glucose uptake in the basal state. ${ }^{3}$ The treatment of $10 \mathrm{~nm}$ insulin without any fractions was used as positive control since $10 \mathrm{~nm}$ insulin maximized insulin-stimulated glucose uptake. ${ }^{4}$ Values were mean \pm standard deviation. ${ }^{5}$ Berberine (BB) contents in each fraction separated by the Amberlite XAD-4 column were determined by HPLC analysis with an external standard and were calculated the following equation; [standard amount $(\mathrm{mg}) \times($ Sample area/Standard area $)] \div$ Sample $(\mathrm{mg}) \times 100$. * Significant CR fraction effect on insulin-stimulated glucose uptake at $p<0.05$, $* *$ at $p<0.01, * * *$ at $p<0.001$. $^{\text {a,b,c }}$ Values on the same column with different superscripts (a, b, c) were significantly different at $p<0.05$ by Tukey test.

Tukey tests. If necessary, the comparison of an experimental group against the positive control was determined by Student $t$-test. $p<0.05$ were considered statistically significant.

\section{RESULTS}

Insulin Dosage Response in 3T3-L1 Adipocytes Insulin-stimulated glucose uptake increased in a dose-dependent manner up to $10 \mathrm{~nm}$ insulin in 3T3-L1 adipocytes. Glucose uptake at $10 \mathrm{~nm}$ insulin was higher than at baseline (no insulin treatment) and $0.2 \mathrm{nM}$ insulin treatment by $6.5 \pm 0.9$ and $4.2 \pm 0.6$ folds, respectively. Insulin-mediated glucose uptake was not further elevated in concentrations of over $10 \mathrm{~nm}$ insulin where the glucose uptake was used as the index of the maximum. In the previous experiment, ${ }^{12)}$ when $20 \mu \mathrm{M}$ trogliazone, an insulin sensitizer, was added to 3T3-L1 adipocytes with $0.2,0.6,1,4$, or $10 \mathrm{~nm}$ insulin, the glucose uptake increased in all dosages. However, troglitazone plus $0.2 \mathrm{~nm}$ insulin elevated the insulin-stimulated glucose uptake to reach the maximum rate of $10 \mathrm{~nm}$ insulin. ${ }^{12}$ ) Thus, the concentration of $0.2 \mathrm{nM}$ insulin was used to find insulin sensitizer candidates from CR fractions in 3T3-L1 adipocytes.

Insulin-Stimulated Glucose Uptake with Fractions of CR Concentrations of $0.05,0.1,0.5,2,5,10,25,50,75$ and $100 \mu \mathrm{g} / \mathrm{ml}$ of $70 \% \mathrm{EtOH}$ extract were used in insulinstimulated glucose uptake in 3T3-L1 adipocytes. Two different concentrations, 0.5 and $5 \mu \mathrm{g} / \mathrm{ml}$, were optimal in determining the insulin sensitizing effects (data not shown). Concentrations of 0.5 and $5 \mu \mathrm{g} / \mathrm{ml}$ were used to determine insulin-stimulated glucose uptake with CR fractions. The 20, 40 and $60 \% \mathrm{MeOH}$ fractions increased an insulin sensitizing action in a dose-dependent manner (Table 1).

Berberine Effects on Insulin-Stimulated Glucose Uptake As the major compound in CR is alkaloid berberine, the berberine contents in each fraction of CR were identified.
The chemical structure of berberine is 5,6-dihydro-9,10dimethoxybenzo(g)-1,3-benzodioxolo(5,6-a) quinolizinium. Berberine was a major component in the 20,40 and $60 \%$ fractions (Table 1). Other than berberine, three to four components were detected in each fraction, but they were minimal.

Five to $50 \mu \mathrm{M}$ of berberine, the equivalent concentration of the 0.5 to $5 \mu \mathrm{g} / \mathrm{ml}$ of the $20 \% \mathrm{MeOH}$ fraction, were treated with $0.2 \mathrm{~nm}$ insulin to determine any insulin sensitizing action. Berberine increased insulin-stimulated glucose uptake in a dose dependent manner, and $50 \mu \mathrm{m}$ berberine was more potent than $5 \mu \mathrm{M}$ (Fig. 1). The low $(5 \mu \mathrm{M})$ and high $(50 \mu \mathrm{M})$ dosages of berberine treatment had the potency similar to 2 and $20 \mu \mathrm{M}$ pioglitazone treatments, respectively. Exendin-4, another positive control, also increased glucose uptake at both the low $(0.5 \mathrm{~nm})$ and high $(2.5 \mathrm{nM})$ dosage, compared to the vehicle (DMSO) treatment. The treatment of $50 \mu \mathrm{M}$ berberine and $20 \mu \mathrm{m}$ pioglitazone stimulated as much as $10 \mathrm{~nm}$ insulin treatment, but $2.5 \mathrm{~nm}$ exendin- 4 exhibited a little lower potency than pioglitazone. Berberine, pioglitazone and exendin-4 did not stimulate glucose uptake without insulin, suggesting that they do not elevate nonspecific glucose uptake and their action takes place in insulin mediated pathways. Thus, the possible action mechanism of berberine, in stimulating glucose uptake, is to enhance insulin signaling cascade in 3T3-L1 adipocytes.

Berberine Effect on Insulin Signaling Cascade Berberine ( 5 or $50 \mu \mathrm{M}$ ) plus $0.2 \mathrm{~nm}$ insulin increased tyrosine phosphorylation of IRS1 to levels as high as those seen with treatment of $10 \mathrm{~nm}$ insulin without changes of its expression level in 3T3-L1 adipocytes (Fig. 2). The serine ${ }^{473}$ phosphorylation of Akt, the downstream signaling molecule of IRS1phosphoinositide 3 Kinase (PI3-Kinase), was increased with berberine. Akt protein contents were not altered (Fig. 2). GLUT4 contents in the membrane were also elevated in cells 
Deoxyglucose uptake (pmol/mg protein)

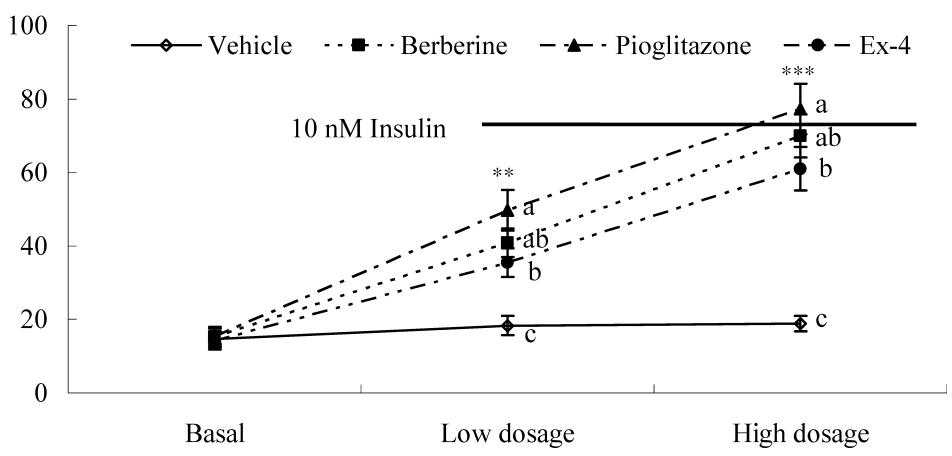

Fig. 1. Insulin-Stimulated Glucose Uptake with Berberine Treatment in 3T3-L1 Adipocytes

Low and high dosages of vehicle (DMSO), berberine (BB; 5, $50 \mu \mathrm{M}$ ), pioglitazone (PG; 2, $20 \mu \mathrm{M}$ ) or exendin-4 (Ex-4; $0.5,2.5 \mathrm{nM})$ were treated for $8 \mathrm{~h}$ in $3 \mathrm{~T} 3-\mathrm{L} 1 \mathrm{adipocytes}$. At the end of the incubation, $0.2 \mathrm{~nm}$ insulin was administered for $30 \mathrm{~min}$ to determine insulin-stimulated glucose uptake representing insulin sensitizing activity. In the basal state, the vehicle (DMSO) was treated without insulin. PG and Ex-4 were used as a positive control. The data were ${ }^{3} \mathrm{H}$-deoxyglucose contents in mg protein of cells, indicating the degree of glucose uptake. $* *$ Significant berberine effect on insulin-stimulated glucose uptake in low and high dosage treatments at $p<0.01, * * *$ at $p<0.001$. ${ }^{\text {ab,c }}$ Values on the same column with different superscripts $(\mathrm{a}, \mathrm{b}, \mathrm{c})$ were significantly different at $p<0.05$ by Tukey test.

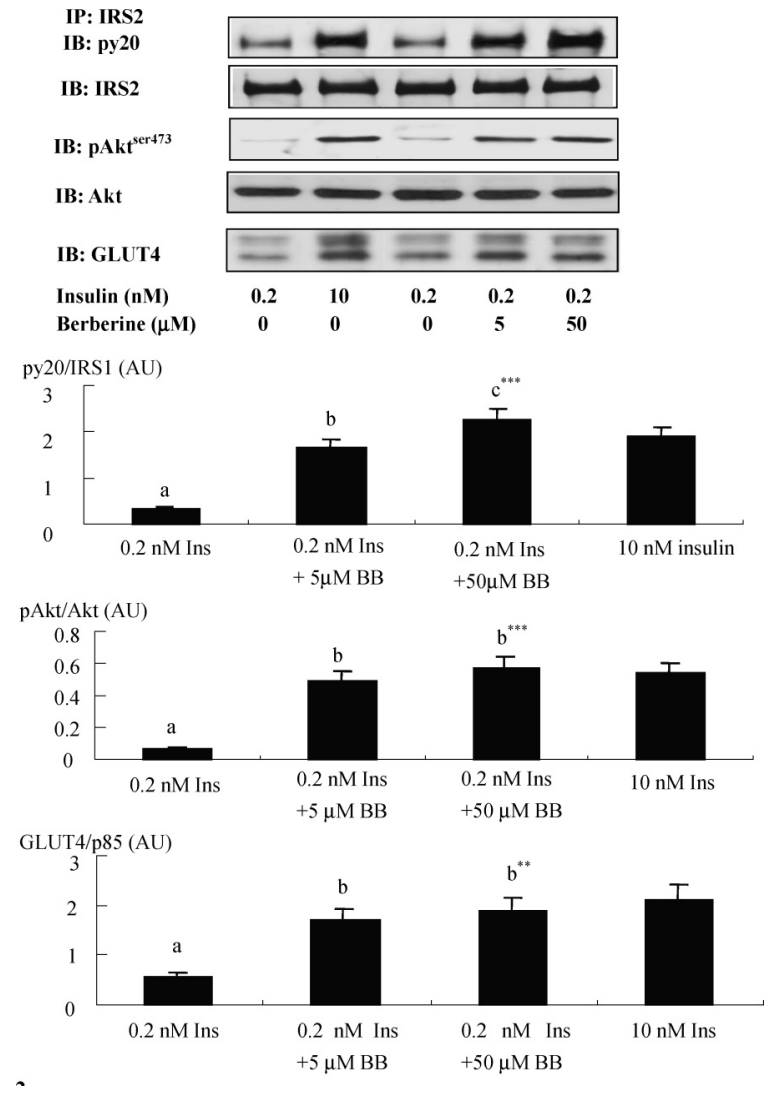

Fig. 2. Changes of the Phosphorylation and Contents of Proteins Associated with Insulin Signaling Cascade in Berberine Treatment in 3T3-L1 Adipocytes

Berberine $(\mathrm{BB} ; 5,50 \mu \mathrm{M})$ and $0.2 \mathrm{~nm}$ insulin was treated for $8 \mathrm{~h}$ in 3T3-L1 adipocytes, and at the end of the incubation, 0.2 or $10 \mathrm{~nm}$ insulin was administered for $10 \mathrm{~min}$. In the basal state, the vehicle (DMSO) was treated without insulin. The cells were lyzed with a lysis buffer and an equal amount of protein was used for immunoblotting analysis. The phosphorylation and expression of IRS1 was measured by immunoprecipitation followed by immunoblotting analysis. The phosphorylation and expression of other proteins, Akt and glucose transpoter (GLUT)-4 was determined with specific antibodies by immunoblotting analysis only. ** Significant berberine effect on protein expression and phosphorylation at $p<0.01, * * * p<0.001$. ${ }^{\mathrm{a}, \mathrm{b}, \mathrm{c}}$ Values on the same column with different superscripts $(a, b, c)$ were significantly different at $p<0.05$ by Tukey test.

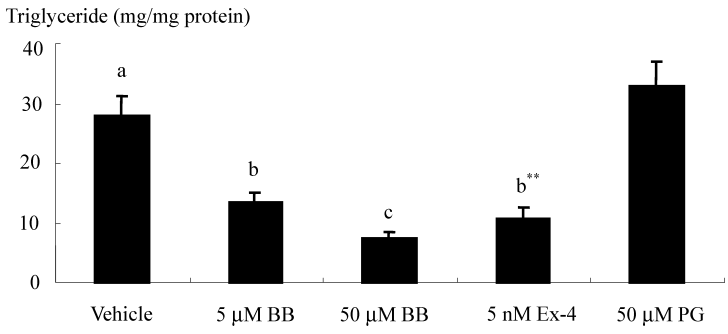

Fig. 3. Triglyceride Accumulation during the Differentiation from 3T3-L1 Fibroblast to Adipocytes

Two days at post-confluence 3T3-L1 fibroblasts in 6 well plates were treated with differentiation inducers for $4 \mathrm{~d}$ and DMSO, 5 or $50 \mu \mathrm{m}$ berberine (BB) until the cells were harvested. At $10 \mathrm{~d}$ after the initiation of induction, the cells were harvested with lysis buffer without glycerol and the triglyceride contents in the cells were measured. The treatment of $50 \mu \mathrm{M}$ pioglitazone (PG) and $5 \mathrm{~nm}$ exendin-4 (Ex-4) was used as a positive control. ** Significant berberine effect on triglyceride accumulation at $p<0.01$. ${ }^{\mathrm{a}, \mathrm{b}, \mathrm{c}} \mathrm{Val}-$ ues on the same column with different superscripts $(a, b, c)$ were significantly different at $p<0.05$ by Tukey test.

treated with berberine (Fig. 2). Thus, increased glucose uptake with berberine plus $0.2 \mathrm{~nm}$ insulin was associated with enhancement of the IRS1-PI3-Kinase-Akt-GLUT4 translocation pathway.

In the absence of insulin, neither berberine nor the vehicle induced phosphorylation of IRS1 at all, even though expression levels were not different from other treatments (data not shown). Akt phosphorylation and GLUT4 translocation, associated with insulin signaling cascade, were not stimulated either. Thus, berberine did not stimulate insulin signaling cascade without insulin. This was consistent with the glucose uptake with berberine alone.

Berberine Effect on Triglyceride Accumulation Berberine remarkably decreased triglyceride accumulation in 3T3-L1 adipocytes in a dose dependent manner (Fig. 3), and $5 \mathrm{~nm}$ exendin-4 decreased triglyceride deposit as well. Unlike berberine and exendin- $4,50 \mu \mathrm{M}$ pioglitazone elevated the accumulation of triglyceride by increased differentiation from 3T3-L1 fibroblast to adipocytes and triglyceride synthesis.

Berberine Effect on Insulinotropic Action As exendin4 is known to have an insulinotropic action, it was used as a positive control. Berberine and exendin-4 did not enhance insulin secretion in low glucose KRP buffer (Fig. 4A), but it increased glucose-stimulated insulin secretion in a dose dependent manner in Min6 cells. Insulin secretion with treatment 

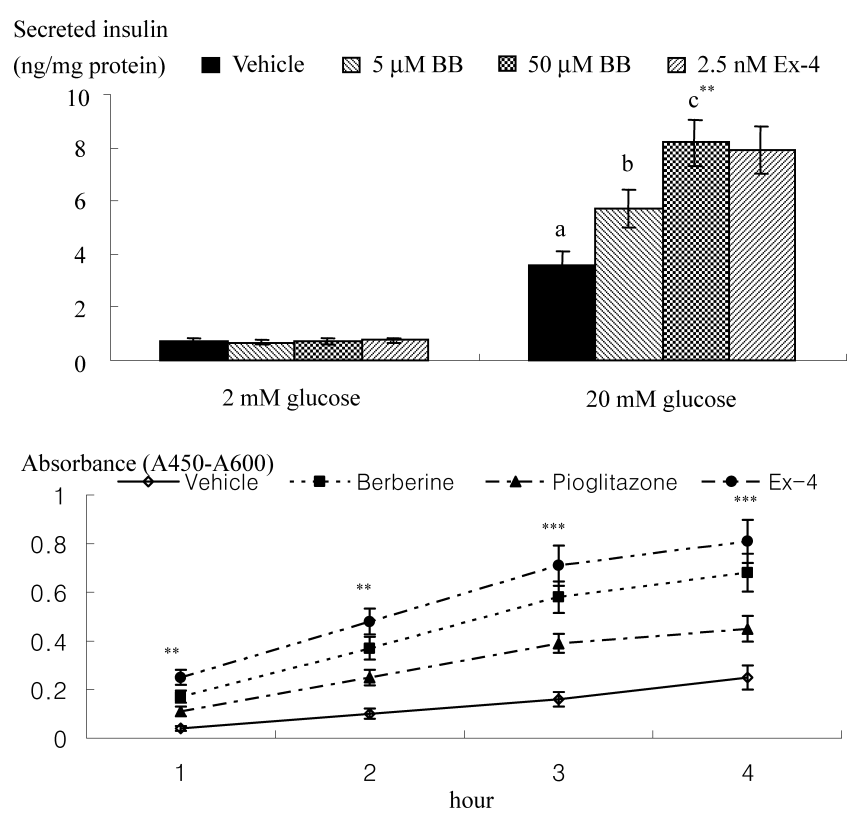

Fig. 4. Glucose-Stimulated Insulin Secretion and Cell Proliferation with Berberine in Min6 Cells

After a $16 \mathrm{~h}$ incubation in low glucose DMEM, the Min6 cells were treated with the vehicle (DMSO), 5 or $50 \mu \mathrm{m}$ berberine (BB) or $2.5 \mathrm{~nm}$ exendin-4 (Ex-4) in low ( $2 \mathrm{~mm}$ ) or high glucose (20 mM) Krebs-Ringer buffer for $30 \mathrm{~min}$ to measure glucose-stimulated insulin secretion (A). Proliferation of Min6 cells (B) was measured by a WST-1 reagent in $1 \times 10^{4}$ cells per well treated with the vehicle (DMSO), 5 or $50 \mu \mathrm{M} \mathrm{BB}$ or $2.5 \mathrm{nM} \mathrm{Ex-4}$ in high glucose DMEM for $4 \mathrm{~h}$. Thereafter, formazan formed with quantitated at $450 \mathrm{~nm}$ with an ELISA plate reader. $* *$ Significant berberine effect on insulin secretion at $p<0.01, * * *$ at $p<0.001$. a,b,c Values on the same column with different superscripts $(\mathrm{a}, \mathrm{b}, \mathrm{c})$ were significantly different at $p<0.05$ by Tukey test.

of $50 \mu \mathrm{M}$ berberine was as high as that which was applied with $2.5 \mathrm{~nm}$ exendin-4. Thus, berberine enhanced glucosestimulated insulin secretion. Berberine as well as exendin-4 increased Min6 cell proliferation in a dose dependent manner measured with a WST-1 reagent (Fig. 4B). Berberine had a tropic action in Min6 cells similar to that expressed by exendin-4.

The survival of Min6 cells and islets was reported to be potentiated by increasing proliferation and decreasing apoptosis through enhancing the insulin/IGF-1 signaling cascade. $^{10,11)}$ Berberine elevated IRS2 expression due to an increase in CREB phosphorylation in Min6 cells in a dose dependent manner (Fig. 5). Induction of IRS2 potentiated its tyrosine phosphorylation in the presence of $10 \mathrm{~nm}$ IGF-1, parallel to the expression levels (Fig. 5). Increased tyrosine phosphorylation of IRS2 potentiated Akt phosphorylation leading to improving insulin/IGF-1 signaling cascade in Min6 cells. The improvement contributed to enhancing the proliferation of Min6 cells. IRS2 phosphorylation and downstream signaling cascade without IGF-1 was also elevated by insulin secreted from Min6 cells. However, the insulin secreted was less potent than IGF-1 by $50-60 \%$ (data not shown). Thus, like exendin-4, berberine enhanced the survival of Min6 cells by induction of IRS2 leading to potentiating insulin/IGF-1 signaling pathways.

\section{DISCUSSION}

In our study, berberine alkaloid rich in CR and Cortex Phellodendri extracts was found to increase insulin-stimu-

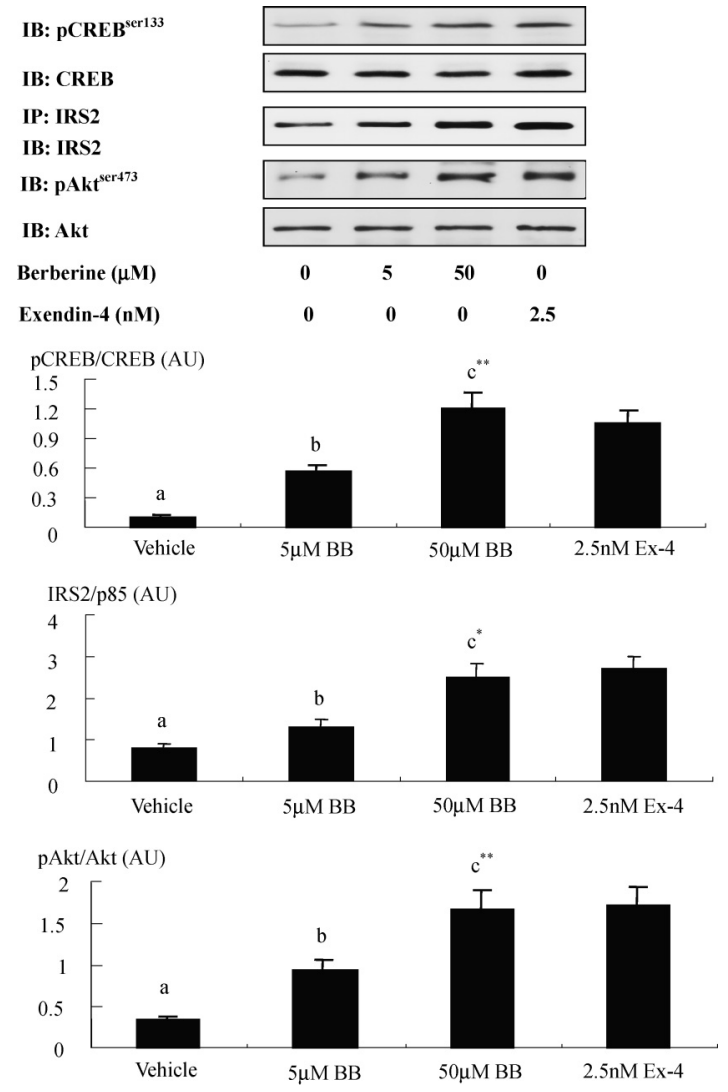

Fig. 5. Changes of the Phosphorylation and Contents of Proteins Associated with Insulin/IGF-1 Signaling Cascade in Berberine Treatment in Min6 Cells

In the basal state, DMSO, instead of both insulin and extracts, was treated. Berberine (BB; $5,50 \mu \mathrm{M}$ ) was treated for $8 \mathrm{~h}$ in Min6 cells, and at the end of the incubation, $10 \mathrm{~nm}$ IGF-1 was administered for $10 \mathrm{~min}$. The treatment of $2.5 \mathrm{~nm}$ exendin- 4 (Ex-4) was used as positive control. The cells were lyzed with a lysis buffer and equal amount of protein were used for immunoblotting analysis. The expression of IRS2 was measured by immunoprecipitation, followed by immunoblotting analysis. The phosphorylation and expression of other proteins, cAMP responding element binding protein (CREB) and Akt was determined with specific antibodies by immunoblotting analysis only. $*$ Significant berberine effect on protein expression and phosphorylation at $p<0.05$, ** at $p<0.01$. a,b,c Values on the same column with different superscripts (a, b, c) were significantly different at $p<0.05$ by Tukey test.

lated glucose uptake as much as pioglitazone, known as an insulin sensitizer, in a cell-based glucose uptake screening assay. Enhanced insulin-stimulated glucose uptake via berberine was associated with increased GLUT4 contents in the membrane via potentiating the IRS1-PI3-Kinase-Akt signaling cascade in 3T3-L1 adipocytes. Unlike pioglitazone, berberine as well as exendin-4, decreased triglyceride accumulation in 3T3-L1 adipocytes. Berberine enhanced glucosestimulated insulin secretion. Furthermore, it potentiated insulin/IGF-1 signaling cascade by IRS2 induction through the activation of CREB in Min6 cells, possibly enhancing $\beta$-cell function and mass. According to the results, berberine acts as an insulinotroic agent similar to exendin-4, and it may be beneficial for treating obese type 2 diabetic patients.

Berberine is an alkaloid from CR, Cortex Phellodendri and other plants. ${ }^{7)}$ It is widely used in traditional Chinese medicine as an antimicrobial and anti-tumor agent. ${ }^{6,17)}$ The ability of cytotoxicity to act as topoisomerase I or II poison was reported to be related to the anti-tumor activity, in which the DNA binding process was of vital importance. However, cytotoxicity was exhibited at the concentration of over 
$200 \mu \mathrm{M}$ in 3T3-L1 adipocytes and Min6 cells in our study (data not shown). Leng et $a l^{6}{ }^{6}$ revealed cytotoxicity in a $100 \mu \mathrm{M}$ berberine treatment. Thus, a low dosage of berberine can be used as the treatment for metabolic disorders without side effects.

Berberine was recently reported to alleviate cardiovascular disease by decreasing low-density lipoproteins via activating $\mathrm{p} 44 / \mathrm{p} 42$ mitogen-activated protein kinase (ERK1/2). ${ }^{18,19)}$ Berberine may relieve metabolic diseases such as type 2 diabetes and cardiovascular disease by altering cell signaling pathways. Recent study has shown that berberine decreased blood glucose levels by increasing insulin secretion in high fat induced glucose intolerant mice, ${ }^{6)}$ and it had a weak capacity to inhibit $\alpha$-glucoamylase. ${ }^{20)}$ However, Yin et al. ${ }^{21)}$ reported that berberine exerts a glucose-lowering action in HepG2 cells up to glucose concentrations of $11.1 \mathrm{~mm}$, but not at $22.2 \mathrm{~mm}$. This was not insulin dependent pathway. Yet, no changes of glucose-stimulated insulin secretion were observed in the $\beta \mathrm{TC} 3$ cell line. This is contradictory to the results of Leng et al. ${ }^{6}$ and this present study. Thus, it is important to scrutinize the anti-hyperglycemic mechanism of berberine in aspects such as insulin sensitizing and insulinotropic action.

In our study, berberine increased glucose uptake as much as exendin-4 and pioglitazone in 3T3-L1 adipocytes. Pioglitazone, as well as trolitazone and rosiglitazone, is well known as an insulin sensitizer which increases triglyceride accumulation in adipocytes through activating the transcription of a peroxisome proliferation activated receptor (PPAR)$\gamma$ and CCAAT/enhancer-binding protein. $^{22,23)}$ However, berberine and exendin-4 decreased the differentiation and triglyceride accumulation when preadipocytes were incubated with berberine and differentiation inducers. Zhou et $a l^{24)}$ and Wang et $a .^{25)}$ also demonstrated that berberine decreased the differentiation of 3T3-L1 preadipocytes and triglyceride accumulation by decreasing PPAR $-\gamma$ expression. Exendin-4 treatment also decelerated body weight gain with reduced subcutaneous and visceral fat along with an amelioration of glucose homeostasis in obese Zucker rats. ${ }^{26)}$ Enhanced insulin-stimulated glucose cannot be involved in triglyceride accumulation and preadipocyte differentiation. Thus, it suggested that berberine and pioglitazone improve insulin action in two different pathways.

Our study showed that 5 to $50 \mu \mathrm{m}$ berberine plus a low dose of insulin enhanced insulin signaling cascade in 3T3-L1 adipocytes via enhancing pIRS1-PI3-Kinase-pAkt. As a result of improved insulin signaling cascade, GLUT4 translocation into the plasma membrane increased. It has been reported that GLUT4 translocation is increased by the activation of PI3-Kinase and Akt. ${ }^{15,27)}$ Activation of insulin receptors by insulin and an insulin sensitizer increased the phosphorylation of specific tyrosine residues on the IRS proteins serving as docking sites for proteins that contain $\mathrm{SH} 2$ domains, such as the p85 regulatory subunit of PI3-Kinase. ${ }^{27)}$ Binding IRS1 and p85activated PI3-Kinase catalyzed the formation of phosphatidylinositol-3,4,5-trisphosphate, an allosteric activator of phosphoinositide-dependent kinase. The kinase phosphorylated Akt on ser-473 and thr-308 sites led to an increase in GLUT4 translocation. ${ }^{15,27)}$ Akt phosphorylation on ser-473 exhibits a better response to diabetic conditions. ${ }^{27)}$ Increased GLUT4 contents in the plasma membrane led to increased glucose uptake. Our study demonstrated that berberine acts as an insulin sensitizer in adipocytes through activating insulin-stimulated glucose uptake through IRS1PI3-Kinase-Akt-GLUT4 translocation pathways without activating PPAR- $\gamma$, unlike troglitazone.

In addition to enhancing insulin-stimulated glucose uptake, berberine increased glucose-stimulated insulin secretion and proliferation in Min6 cells in our study. Berberine increased insulin secretion in Min6 cells consistent with the results from Leng et al. ${ }^{6}$ ) Moreover, we showed that berberine worked not only as insulin secretagogue but also as an insulinotropic agent. The mechanism was closely associated to IRS2 induction in Min6 cells. Berberine activated CREB phosphorylation in Min6 cells, resulting in enhancing insulin/IGF-1 signaling cascade by the induction of IRS2 expression. The activation of CREB has been reported to induce IRS2 expression since human and murine Irs 2 genes contain several half-cre elements in the $5^{\prime}$-untranslated region that bind to phosphorylated CREB. ${ }^{11)}$ Jhala et al. ${ }^{11)}$ demonstrated that exendin- 4 induced IRS2 expression by the activation of CREB in Min6 cells and islets, which activated Akt in response to an insulin/IGF-1 signaling cascade, leading to increased $\beta$-cell mass by increasing proliferation of $\beta$ cells and decreasing apoptosis. Thus, berberine can increase $\beta$-cell mass by increased $\beta$-cell proliferation and decreased apoptosis like exendin-4 via the activation of CREB. ${ }^{11,28)}$ Meanwhile, it has been reported that the phosphorylation of CREB is induced by the activation and the nuclear translocation of ERK1/2 by glucagon in Min6 cells and isolated islets. $^{29,30)}$ Berberine also increased the phosphorylation of ERK1/2 in hepatoma cells. ${ }^{18)}$ Thus, berberine possibly increased the proliferation and survival of Min6 cells, $\beta$-cell line, via pERK1/2-pCREB-IRS2 pathways. Berberine worked as an insulinotropic agent with the same mechanism of exendin-4 in Min6 cells.

In conclusion, alkaloid berberine, a major component of $\mathrm{CR}$ and Cortex Phellodendri, has similar characteristics of exendin-4, an insulin sensitizing and insulinotropic agent. It had an effective insulin sensitizing action which increased insulin-stimulated glucose uptake and decreased triglyceride accumulation via enhancing pIRS1-PI3-Kinase-pAktGLUT4 translocation in 3T3-L1 adipocytes. It also enhanced insulinotropic action via pCREB-pIRS2-pAkt. Thus, berberine can be beneficial for use as an anti-diabetic agent for obese type 2 diabetic patients.

Acknowledgment This work was supported by a grant from the Department of Public Health and Welfare (02-PJ9PG1-CO02-0002) of Korea in 2002.

\section{REFERENCES}

1) Ward W. K., Beard J. C., Halter J. B., Pfeiffer M. A., Porte D., Diabetes Care, 7, 491-502 (1984).

2) Olmez E., Ilhan M., Arzneimittelforschung, 42, 1095-1097 (1992).

3) Shin D. H., Yu H., Hsu W. H., Life Sci., 53, 1495-1500 (1993).

4) Ahren B., Lundquist I., Acta Physiol. Scand., 125, $211-217$ (1985).

5) Dunne M. J., Br. J. Pharmacol., 103, 1847-1850 (1991).

6) Leng S. H., Lu F., Xu L. J., Acta Pharmacol. Sin., 25, 496-502 (2004).

7) Melander A., Lebovitz H. E., Faber O. K., Diabetes Care, 13, S18S25 (1990).

8) Vilsboll T., Holst J. J., Diabetologia, 47, 357-366 (2004). 
9) Malendowicz L. K., Macchi C., Nussdorfer G. G., Nowak K. W., Zyterska A., Ziolkowska A., Int. J. Mol. Med., 11, 763-766 (2003).

10) Xu G., Stoffers D. A., Habener J. F., Bonner-Weir S., Diabetes, 48, 2270-2276 (1999).

11) Jhala U. S., Canettieri G., Screaton R. A., Kulkarni R. N., Krajewski S., Reed J., Walker J., Lin X., White M. F., Montminy M., Genes Dev., 17, 1575-1580 (2003).

12) Choi S. B., Jun D. W., Park S., Life Sci., 75, 2653-2664 (2004).

13) Usui I., Imamura T., Huang J., Satoh H., Olefsky J. M., J. Biol. Chem., 278, 13765-13774 (2003).

14) Hennige A. M., Burks D. J., Ozcan U., Kulkarni R. N., Ye J., Park S., Schubert M., Fisher T. L., Dow M. A., Leshan R., Zakaria M., MossaBasha M., White M. F., J. Clin. Invest., 112, 1521-1532 (2003).

15) Kotani K., Ogawa W., Hashiramoto M., Onishi T., Ohno S., Kasuga M., J. Biol. Chem., 275, 26390-26395 (2000).

16) Committee of SAS Institute, "Guide for personal computers," SAS Institutes Inc, Cary, NC, 1985, pp. 257-260.

17) Freile M. L., Giannini F., Pucci G., Sturniolo A., Rodero L., Pucci O., Balzareti V., Enriz R. D., Fitoterapia, 74, $702-705$ (2003).

18) Kong W., Wei J., Abidi P., Lin M., Inaba S., Li C., Wang Y., Wang Z., Si S., Pan H., Wang S., Wu J., Wang Y., Li Z., Liu J., Jiang J. D., Nat. Med., 10, 1344-1351 (2004).

19) Lau C. W., Yao X. Q., Chen Z. Y., Ko W. H., Huang Y., Cardiovasc.
Drug Rev., 19, 234-244 (2001).

20) Pan G. Y., Huang Z. J., Wang G. J., Fawcett J. P., Liu X. D., Zhao X. C., Sun J. G., Xie Y. Y., Planta Med., 69, 632-636 (2003).

21) Yin J., Hu R., Chen M., Tang J., Li F., Yang Y., Chen J., Metabolism, 51, 1439-1443 (2002).

22) Bogacka I., Xie H., Bray G. A., Smith S. R., Diabetes Care, 27, $1660-1667$ (2004).

23) Verma N. K., Singh J., Dey C. S., Br. J. Pharmacol., 143, 1006-1013 (2004).

24) Zhou L. B., Chen M. D., Wang X., Song H. D., Yang Y., Tang J. F., Li F. Y., Xu M. Y., Chen J. L., Zhonghua Yi Xue Za Zhi, 83, 338-340 (2003).

25) Wang S. H., Wang W. J., Wang X. F., Chen W., Zhongguo Zhong Xi Yi Jie He Za Zhi, 24, 926-928 (2004).

26) Szayna M., Doyle M. E., Betkey J. A., Holloway H. W., Spencer R. G., Greig N. H., Egan J. M., Endocrinology, 141, 1936-1941 (2000).

27) Alessi D. R., Cohen P., Curr. Opin. Gene Dev., 8, 55-62 (1998).

28) Li Y., Hansotia T., Yusta B., Ris F., Halban P. A., Drucker D. J., J. Biol. Chem., 278, 471-478 (2003).

29) Dalle S., Longuet C., Costes S., Broca C., Faruque O., Fontés G., Hani E. H., Bataille D., J. Biol. Chem., 279, 20345-20355 (2004).

30) Skoglund G., Hussain M. A., Holz G. G., Diabetes, 49, 1156-1164 (2000). 